\title{
PERBAIKAN POLA TANAM LAHAN KERING DENGAN PENDEKATAN CIRCULAR ECONOMY MENUJU AGRO-EKOWISATA
}

\author{
Melinda R.S. Moata ${ }^{1 \#)}$, Vinni D. Tome ${ }^{2 *)}$, Stefanus Kuang ${ }^{1)}$, Blasius Gharu ${ }^{1)}$ \\ \#Jurusan Manajemen Pertanian Lahan Kering, Politeknik Pertanian Negeri Kupang \\ Jl. Prof. Dr. Herman Yohanes, Kel. Lasiana Kupang-NTT \\ ${ }^{1}$ melinda.moatalstaff.politanikoe.ac.id \\ melinda.moata@gmail.com; ${ }^{3}$ stef130976@yahoo.co.id \\ ${ }^{4}$ blasius.gharuestaff.politanikoe.ac.id \\ *Tanaman Pangan dan Hortikultura, Politeknik Pertanian Negeri Kupang \\ Jl. Prof. Dr. Herman Yohanes, Kel. Lasiana Kupang-NTT \\ ${ }^{2}$ vinni.tomedstaff.politanikoe.ac.id
}

\begin{abstract}
Abstrak
Desa Oelbiteno merupakan salah satu desa dari empat desa yang ada di Kecamatan Fatuleu Tengah yang merupakan salah satu tempat wisata alam di Kab. Kupang-NTT. Daerah ini memiliki potensi pengembangan agroekowisata. Namun sistem pertanian rakyatnya masih bersifat konvensional. Karena itu, untuk peningkaan pertumbuahan eknomi desa dan masyarakat perlu adanya alih guna lahan dari pertanian campuran subsistem menjadi agroekowisata. Diikuti oleh peningkatan produktivitas lahan melalui perbaikan pola tanam lahan kering sesuai kearifan lokal. Kegiatan ini adalah pemberdayaan masyarakat melalui desain kebun model pertanian lahan kering, membimbing dan mendampingi petani agar usaha taninya dapat bernilai ekonomis dan mempunyai dampak ekologi yang baik. Dengan memanfaatkan beberapa objek alam (mata air dan kolam), produk pertanain lahan kering dengan pola tanam bedengan sejajar kontur, dan aplikasi pertanian organik berbahan local dengan pendekatan circular economy telah menambah pemahaman, sikap dan ketrampilan dalam rangka upaya perbaikan pertanian lahan kering yang sehat dan berkelanjutan.
\end{abstract}

Kata Kunci - circular economy, pertanian organik, pola tanam lahan kering

\section{PENDAHULUAN}

Circular Economy (CE) pertama kali diperkenalkan di China tahun 1998 dan secara formal diterima tahun 2002 oleh pemerintah pusat sebagai strategi baru pembangunan (Yan, Z, et al., 2008). Model CE adalah tarnsformasi dari model linear economy (LE) (Kirchherr et al, 2017; Potting, 2017). Model LE menerapkan proses linear sederhana dari produsenkonsumen-limbah berbasis tujuan ekonomi dengan sedikit perhatian untuk ekologi dan social, tetapi CE berbasis masalah, produksi, konsumsi dan dampaknya dengan memperhatikan ketahanan sumberdaya, efisiensi ekosistem alami, pemamfaatan produk dengan cara memperbaiki (repair), memperbaharui (refurbishment), menggunakan produk lagi (reuse) sebelum selesai masa produk tersebut (Sauve et. al. 2016). Untuk bidang pertanian, CE berkaitan dengan sirkulasi material yang ada dalam ekosistem alami dengan mempertimbangkan keseimbangan antara ekonomi dan ekosistem melalui penggunaan kembali sumberdaya pertanian reducing, reusing dan recycling dalam produksi (Jun and Xiang, 2011). Dengan demikian CE bertujuan untuk mengembangkan ekonomi, menjaga lingkungan dan memelihara sumberdaya. Karena itu pembangunan pertanian yang berkelanjutan sebaiknya berdasar pada circular economy karena cocok untuk mengatasi masalah pedesaan, misalnya polusi lingkungan, kerusakan ekologi, dan penipisan sumber daya akibat pertanian konvensional.
Penerapan model CE tepat dilakukan untuk mendukung pembagunan pertanian berkelanjutan karena produk pertanian adalah produk alami yang mudah didaur ulang (recycling), pertanian berkaitan dengan pangan manusia dan industry pertanian selalu bersinergis dengan kehutanan, perikanan, peternakan, pengolahan hasil pertanian, pemasaran dan konsumsi (Jun and Xiang, 2011). Agro-CE memegang prinsip sesuai kondisi lokal, koeksistensi biologi dan saling menguntungkan, koordinasi, penutupan hijau, kehilangan tanah rendah \& perlindungan sumberdaya lahan, aliran sumberdaya, struktur ekonomi, jaringan eco-industry, keuntungan social-ekonomi-ekologi dan management yang komprehensif.

Kabupaten Kupang sebagai kabupaten di propinsi Nusa Tenggara Timur (NTT) masih mengandalkan sector pertanian, perkebunan dan peternakan sebagai sector terbesar penyumbang PDRB. namun pertumbuhan ekonomi untuk ketiga sektor ini menurun dari tahun ke tahun. Padahal usaha tani tidak hanya budidaya tetapi juga dapat sebagai sumber objek wisata alam. Salah satu contoh adalah gunung batu Fatuleu yang terletak di kecamata Fatuleu tengah telah menjadi daya tarik para wisatawan yang berkujung setiap minggu. Hal ini merupakan peluang untuk pertumbuhan ekonomi rakyat yang tinggal di daearah sekitarnya. Desa oelbiteno merupakan salah satu desa dari empat desa yang ada di kecamatan Fatuleu Tengah, juga 
memiliki potensi pengembangan agroekowisata. Namun sistem pertanian rakyatnya masih bersifat konvensional. Karena itu, untuk peningkatan pertumbuahan ekonomi desa dan masyarakat perlu adanya alih guna lahan dari pertanian campuran subsistem menjadi agroekowisata. Diikuti oleh peningkatan produktivitas lahan melalui perbaikan pola tanam lahan kering sesuai kearifan lokal. Kegiatan ini adalah pemberdayaan masyarakat melalui perbaikan pola tanam lahan kering, membimbing dan mendampingi petani agar usaha taninya dapat bernilai ekonomis dan mempunyai dampak ekologi yang baik. dengan memanfaatkan beberapa objek alam (mata air dan kolam) dan pertanain lahan kering dengan pola tanam bedengan sejajar kontur, system pertanian LEISA (low external input sustainable agriculture) dengan pendekatan circular economy pertanian, diharapkan dapat memberi peluang usaha agroekowisata sehingga ekonomi masyarakat dan desa dapat meningkat.

Kegiatan ini telah dimulai sejak awal tahun 2018 (Februari) dan berakhir di akhir tahun (Nopember 2018). Berdasarkan hasil survey awal pada lokasi ini, maka ditemukan adanya beberapa kendala yang perlu diperbaiki atau dikembngkan. Kendalakendala itu seperti: 1) Topografi bergelombang, sebagian permukaan tanah ditutupi batuan dan bekadar liat tinggi sehingga sulit diolah. 2) Usaha tani konvensional: budidaya tanaman dengan bedengan dengan membakar serasah di atas bedengan sebelum ditanam untuk menamnah kesuburan tanah, lemahnya manajemen pakan dan limbah ternak, belum adanya upaya pemeliharaan kesuburan tanah \& konservasi air, irigasi bergantung air hujan dan air dari bak penampungan yang dipakai bersama oleh masyarakat sekitar (sumber air satu dan dipakai bersama oleh sekitar 10 $\mathrm{KK})$; 3) produksi pertanian rendah karena produktivitas lahan rendah. Produktivitas lahan dipengaruhi oleh kondisi lahan dan populasi tanaman, dan 4) Ekonomi rumah tangga rendah.

Beberapa kegiatan yang telah dilakukan yaitu pembuatan kolam sumber air irigasi dan saluran irigasi, pembuatan bedengan sejajar kontur, bantuan benih, pembuatan pupuk organic bokashi dan cair, pengendali alami OPT (organisme pengganggu tanaman), pestisida alami dengan dukungan bantuan teknologi mesin pembuat pupuk organic (chopper dan mixer) dan pompa air. mesin ini multifungsi dimana selain dimanfaatkan untuk membuat pupuk organic juga pakan ternak.

\section{METODE PELAKSANAAN}

Kegiatan PKM yang telah dilaksanakan adalah:

a. Persiapan dan koordinasi FGD (Focus Group Discussion): pertemuan tim PKM Politani Kupang dengan aparat desa, kelompok tani mitra dan masyarakat untuk pembahasan program, evaluasi dan penentuan lokasi.

b. Kegiatan persiapan: pengolahan tanah, irigasi, persiapan bahan dan alat untuk pupuk dan perstisida organic

c. Pendampingan, monitoring dan evaluasi

Kegiatan teknis pertanian meliputi:

1. Pembuatan bedengan teras kebun

2. Pengadaan air irigasi dengan pembuatan kolam air yang dibantu mesin pompa air dan dipasang pipa paralon sepanjang $350 \mathrm{~m}$.

3. Pemeliharaan rumput lokal dimana biomassnya dijadikan mulsa dan pakan ternak.

4. Pembuatan bak pengomposan

5. Pengadaan mesin multifungsi (chopper dan mixer) untuk pupuk organic dan pakan ternak

6. Pembuatan bokashi dari kotoran sapi dan sisa tanaman yang ada disekitar lokasi.

7. Persiapan lubang untuk biopori ukuran 40x40x40 $\mathrm{cm}^{3}$ dan diisi dengan bokashi atau pupuk kandang yang telah dicampur tanah.

8. Persiapan bibit tanaman untuk tanaman semusim dan bedengan untuk tanaman Jagung, Labu, Kacang, Tomat, kangkung dalam satu lubang yang dilakukan oleh kelompok tani mitra, mahasiswa Politani Kupang yang memprogram MK Kesuburan Tanah dan Nutrisi Tanaman didampingi oleh tim PKM.

9. Pemberian Bio-Mulsa dari biomass rumput yang menutupi seluruh permukaan tanah.

10. Pembuatan pupuk organik cair dan pestisida alami

11. Pembuatan perangkap hama (OPTorganisme pengganggu tanaman) dari botol bekas.

Semua kegiatan di atas dilakukan oleh kelompok tani mitra dan mahasiswa Politani Kupang yang memprogram mata kuliah yang berkaitan serta tim PKM. Bedengan sejajar kontur dengan menerapkan konsep LEISA (Low External Input Agriculture) dan penggunaan mulsa dan pupuk organik in-situ dalam rangka implemantasi metode Circular Economy sebagai salah satu strategi tepat untuk keberlanjutan produksi pertanian di lahan kering.

\section{HASIL YANG DICAPAI}

a. Survey, koordinasi, FGD dan persiapan Survey lokasi tujuan PKM (penentuan lahan untuk demplot) pada 20 January 2018 untuk mengevaluasi kembali kondisi lahan petani. Pada 19Mei 2018 dilakukan FGD dengan aparat desa, kelompok tani, dan anggota 
masyarakat dan hasil kesepakatan didapatkan beberapa usulan penetapan program kegiatan, waktu dan lokasi. Lokasi ditetapkan berdasarkan evaluasi sumber air untuk irigasi, penentuan model irigasi, aksesibility/ infrastruktur, lahan dan pengawasan.

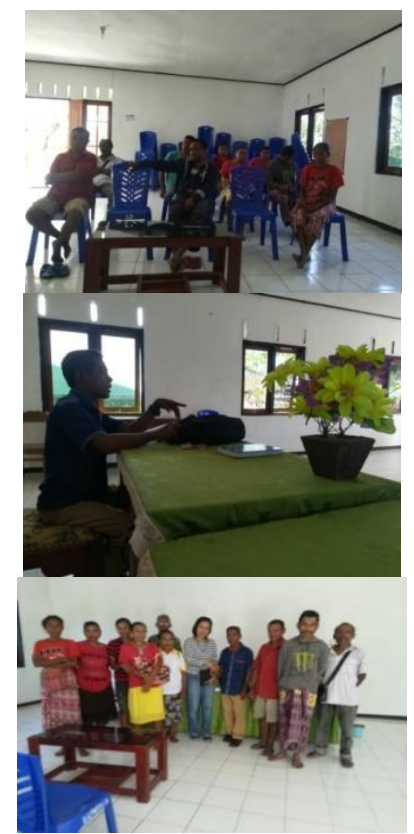

Fig.1-3. FGD tim PKM dengan aparat desa, kel. Tani \& masyarakat

Sarana jalan masuk ke lokasi demplot sebelumnya yang berbatu \& berluang. Selanjutnya pembersihan lahan (pemberantasan gulma, penentuan kontur dan pembuatan teras) dilakukan pada 26 Mei 2018.

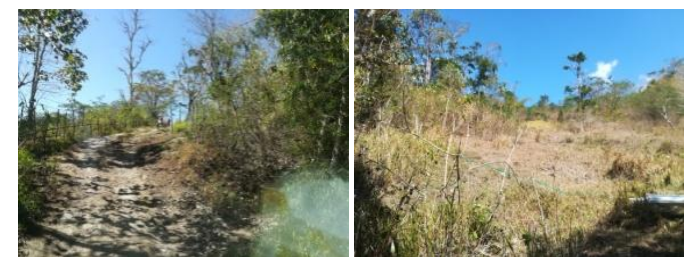

Fig.4-5. Kondisi sarana jalan (sebelum renovasi) dan lahan

Pola tanam lahan kering yang dilakukan petani sebelumnya

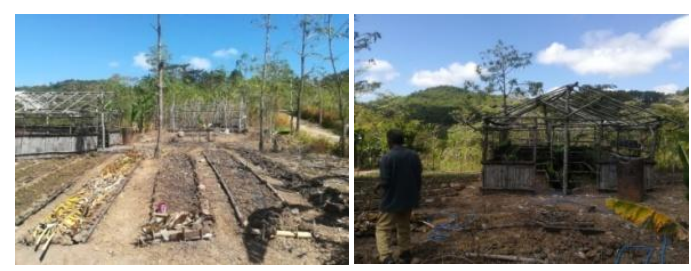

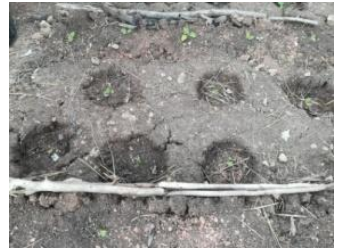

Fig.4-5. Kondisi 6-8 (Kondisi lahan petani sebelumnya)

Pola tanam monokultur, bedengan dengan membakar serasah di atas bedengan. Sumber air berasal dari bak penampunag dan cek dam yang dipakai bersama oleh semua keluarga petani sekitar dan lubang tanam tanpa pupuk organic

b. Persiapan lahan
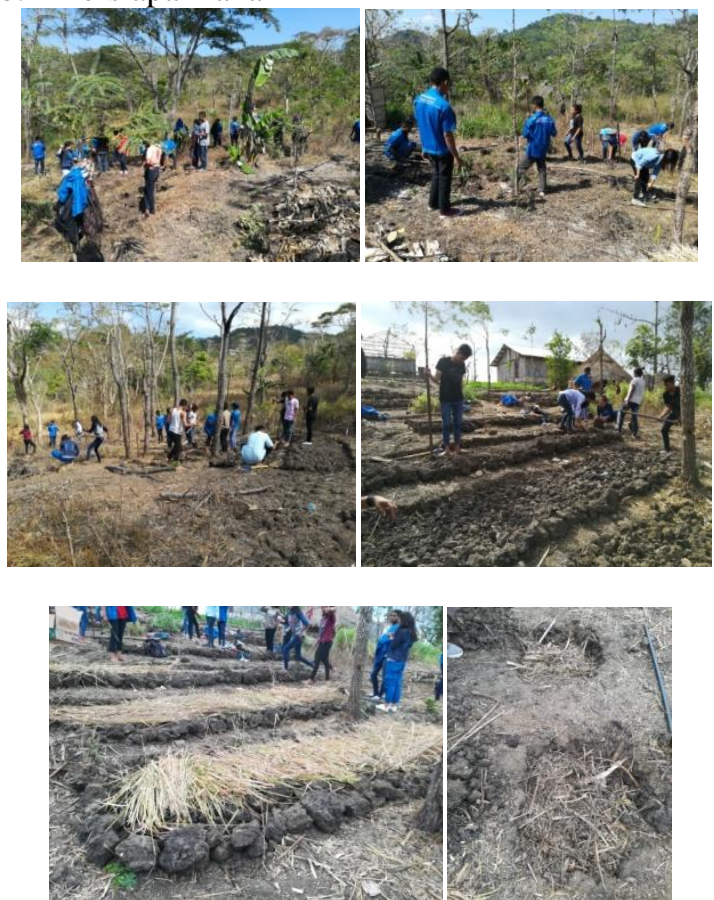

Fig 9-14. Bedengan sesuai kontur lereng; bedengan dengan mulsa organic dari rumput local; dan biopori campuran kotoran ternak dan bahan organic lain.

Persiapan lahan, bahan dan pembuatan pupuk organic dan kotoran ternak: demonstrasi pembuatan Bokashi, pembuatan teras dan bedengan, persiapan bahan untuk pupuk dan pakan ternak, pestisida alami dilakukan pada 9 Juni 2018.

Lahan yang dipakai adalah lahan berlereng dengan kemiringan sekitar 20\%. Tanahnya berat dengan tekstur lempung berliat, kedalaman tanah $>1 \mathrm{~m}$, batuan diperkukaan tanah rendah $<1 \%$. Tingkat kesuburan masih dianggap rendah karena kurang bahan organic, permeabilitas rendah, tingkat aliran permukaan cukup tinggi. Pada lapiran tanah $>30 \mathrm{~cm}$ 
terdapat horizon yang mengandung mineral seperti Fe dan Mn (obervasi dari warna tanah dimana tanah kekuingan dan merah). Kadar airnya cukup baik. Pengadaan mesin mutifungsi untuk pembuatan pupuk organic dan pakan ternak (chopper dengan mesin disel dan mixer manual) pada 28 Juli 2018. Hasilnya adanya mesin chopper dan mixer yang dapat digunakan untuk pembuatan pupuk organic dan pakan ternak.

c. Sumber air irigasi dan pemasangan pipa untuk irigasi $(350 \mathrm{~m})$

Persiapan lahan dan pemasangan irigasi: pembuatan kolam penampung air dari mata air dibuat pada tanggal 7 Juli 2018. Sumber air yang ada berjarak sekitar $350 \mathrm{~m}$ dari lokasi demplot PKM. Mata air tersebut memiliki debit dan volume yang sangat kecil. Oleh karena itu, hasil diskusi tim PKM bersama kepala desa dan mitra memutuskan untuk membuat kolam (micro pond) untuk menampung air pada badan air dari sumber mata air itu. Sumber mata air dimanfaatkan untuk air minum sehingga untuk irigasi dipakai dari penampungan di badan sungai. Micro pond dilakukan dengan menggali kolam, menegeluarkan lumpur dan batuan kecil, meletakkan batuan besar pada dasar kolam, membendung kolam dengan batuan besar dan karung yang diisi tanah liat. Disekitar dinding kolam di lapisi dengan batuan sehingga menahan longsoran dari dinsing.

Pada awalnya air yang tertampung dalam micro pond tersebut masih mengandung lumpur, sehingga belum bisa di pasang mesin pompa air. Setelah beberapa hari dimana airnya sudah jernih, lalu dipasang mesin pompa air. Selanjutnya pemasangan pipa irigasi dilakukan pada 14 Juli 2018 secara 3 tahap karena mempertahankan posisi pipa tegak lurus. Hal ini dilakukan untuk mempertahankan kecepatan air mengalir karena beda tinggi antara sumber air dan lahan demplot sekitar 5 meter dengan jarak 350m. Pipa yang digunakan juga berbeda diameternya dari diameter $3 / 4$ dim beralih ke 1/2 dim agar tolakan airnya dapat mencapai 350m. Setelah 4 minggu melalukan persiapan ini baru akhirnya air itu dapat mencapai lokasi PKM dengan debit dan kecepatan yang cukup memadai. Pada 28 Juli 2018 kegiatan pembuatan lubang biopori untuk Bio-Tumul, penutupan bedengan dengan mulsa organic. Hasilnya adanya sumber air sendiri untuk irigasi yang dekat dengan lokasi demplot dan lubang tanam yang siap ditanami.

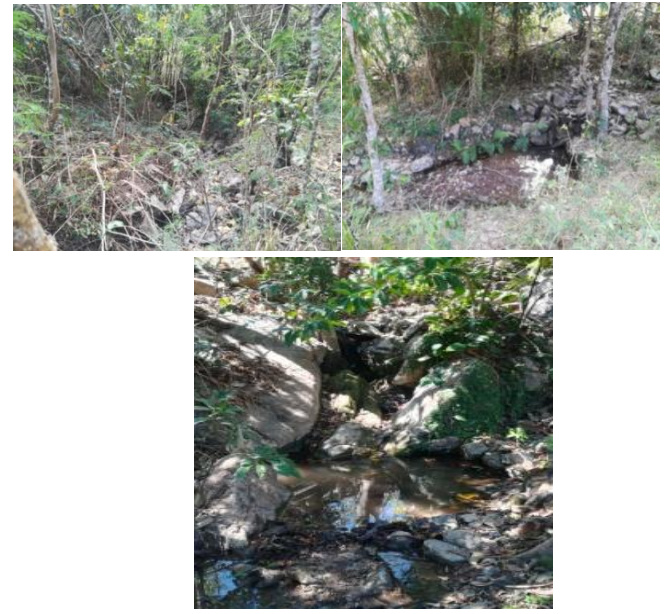

Fig. 15-17 Lokasi sumber air di tengah hutan sekunder 400m dari lahan demplot; b) kondisi air dengan debit dan volume sangat kecil; c) mata air dari celah bebatuan

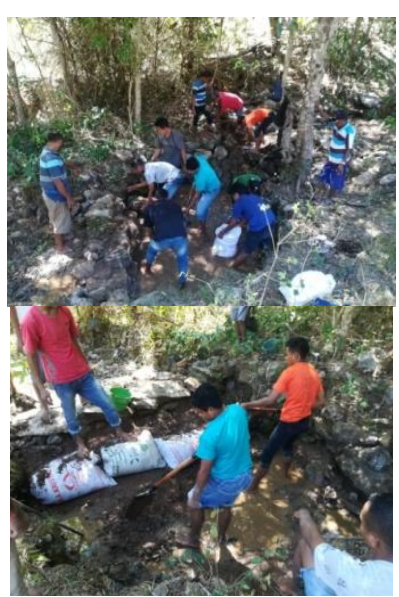

Fig. 18-19. Pengerukkan dasar kolam; Penahanan dinding dan dasar kolam dengan batuan \& tanah

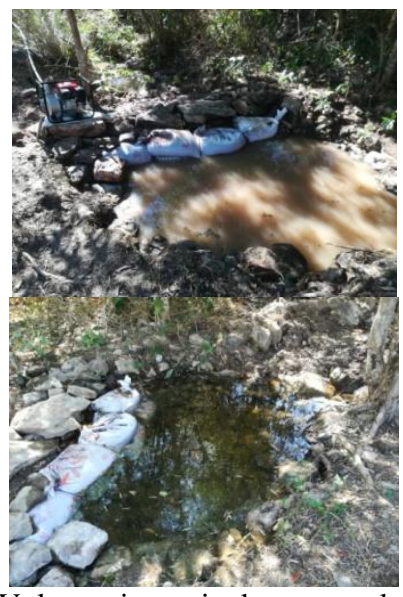

Fig 20-21. Volume air meningkat namun kolam masih keruh; kondisi air dalam kolam yang jernih, pemasangan mesin pompa air 


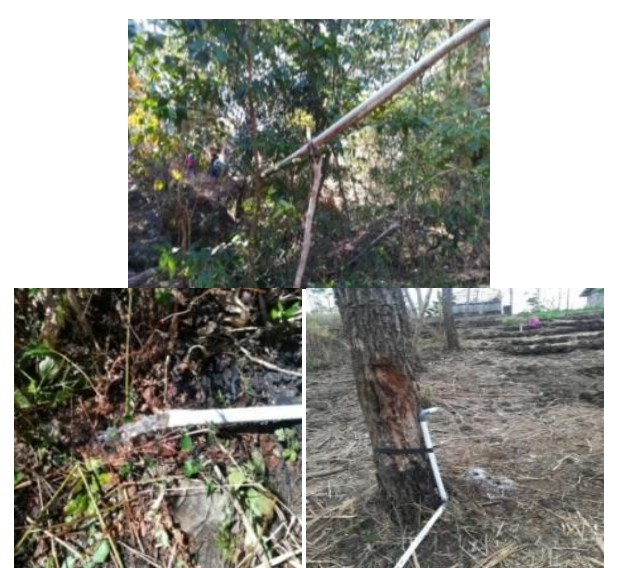

Fig. 22-24. Pemasangan pipa irigasi 3 tahap hingga air dapat mencapai lokasi PKM (350m dari sumber air)

d. Pemupukan organic dan pestisida alami Persiapan bahan dan material untuk pembuatan pupuk organic padat (bokashi) dan pestisida alami serta pengadaan benih sayuran, tanaman pangan (jagung, kacang, tomat, kangkung) dan legume cover crop (criteria ternatea) berfungsi sebagai penutup tanah \& pakan ternak. Benih tanaman yang dipakai berasal dari hasil hybrid dan local. Hasilnya: tersedianya bahan dan alat untuk pembuatan pupuk organic, pestisida alami, dan benih tanaman serta cover crop.

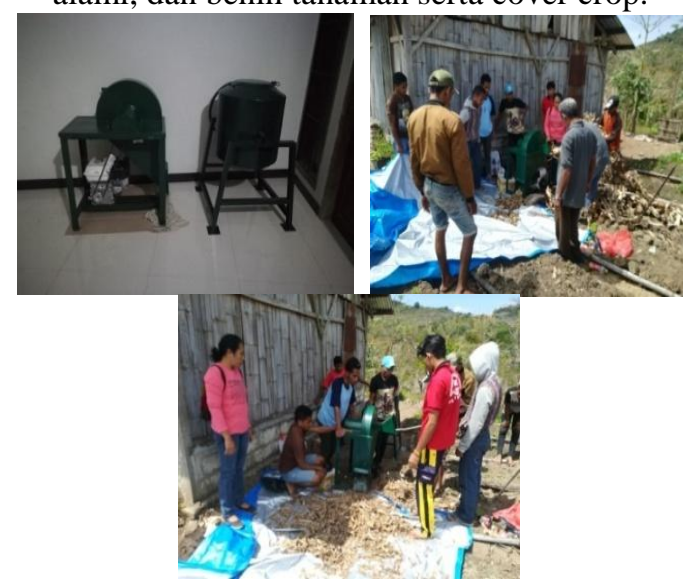

Fig. 24-26. Mesin multifungsi untuk pupuk organic dan pakan ternak. Demonstrasi penggunaan mesin chopper dan mixer

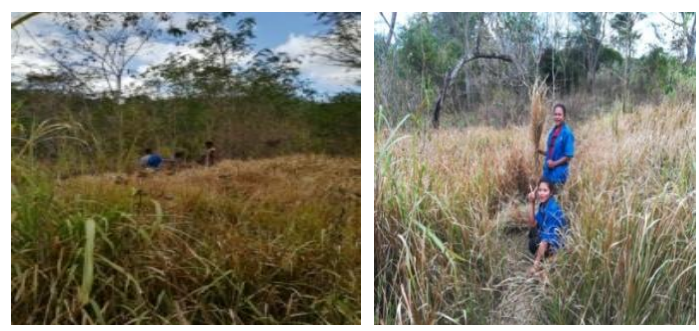

Fig. 27-28. Rumput lokal yang dipakai untuk mulsa organic, pupuk organic dan pakan ternak
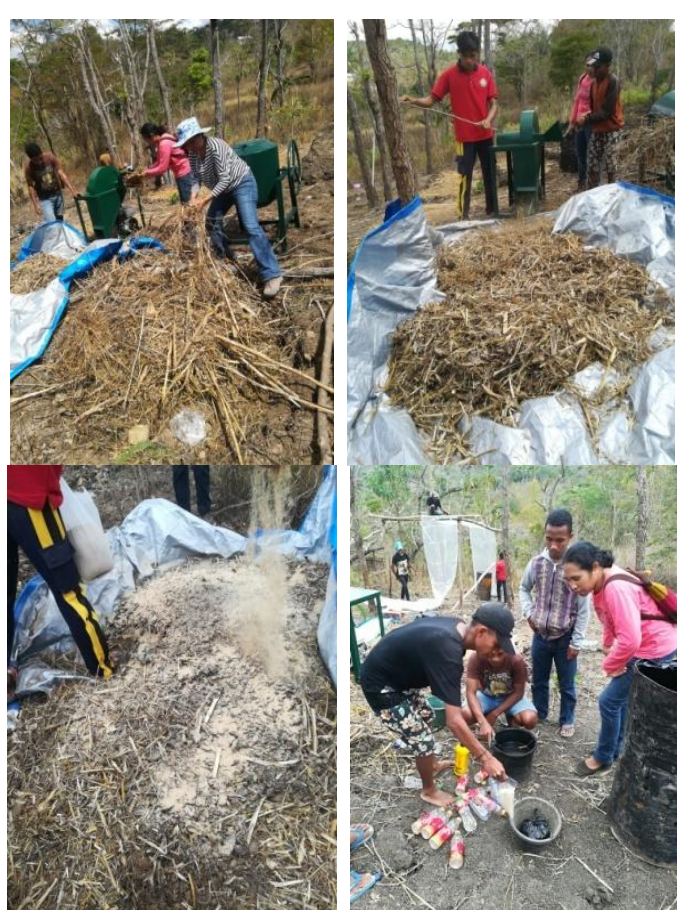

Fig 29-32. Pemotongan bahan-bahan untuk Bokashi; Bahan yang telah dipotong; Bahan dicampur dedak dan kotoran ternak; Pembuatan larutan stock dan pencampuran larutan gula \& EM4

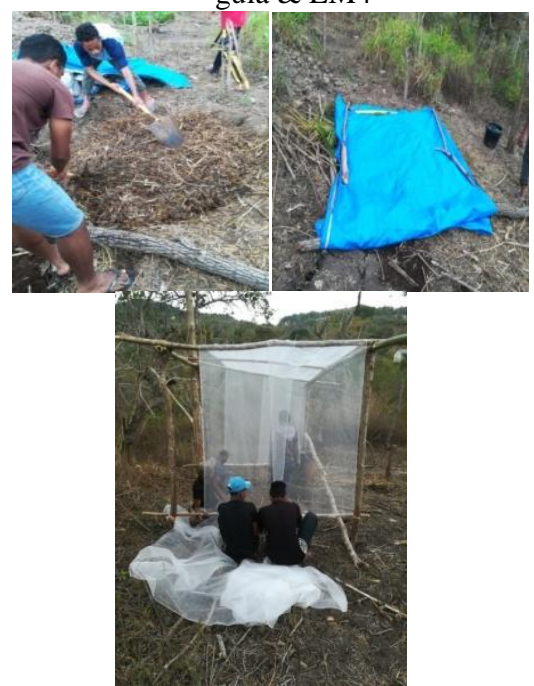

Fig. 32-34. Pencampuran semua bahan bokashi; bak untuk difermentasi beberapa hari; rumah pembibitan
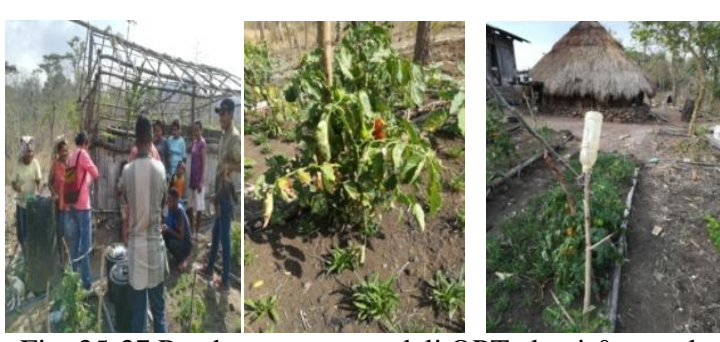

Fig. 35-37.Pembuatan pengendali OPT alami \& pupuk cair; Aplikasi pengendali hama/penyakit 
Pendampingan mitra, monitoring dan evaluasi dilakukan bersama setiap 2 minggu sekali atau sesuai kebutuhan.

Pendekatan circular economy yang diterapkan pada desa Oelbiteno ini menyangkut pemanfaatan semua input dalam (in-situ) dan menekan input-luar masuk dengan reusing (rumput local, limbah pertanian), recycling botol bekas (perangkap hama) dan refurbishment pemberbaharui sumber air (pembuatan micro pond). Dengan peneparan ini, maka menekan biaya input luar (pupuk kimia, pestisida, mulsa plastik, dan pembelian air). Sehingga dampak yang dirasakan bukan saja untuk ekologi dengan meminimalisasi limbah, tetapi juga ekonomi (pengurangan biaya produksi).

\section{KESIMPULAN}

Kegiatan PKM dengan topik "Perbaikan Pola Tanam Lahan Kering dengan pendekatan circular economy menuju Agroekowisata" meliputi kegiatan persiapan (pertemuan, evaluasi, penentuan lokasi), pembersihan lahan dan pembuatan bedengan terasering dengan mulsa organic; pembuatan kolam air dan instalasi pipa irigasi (sepanjang $350 \mathrm{~m}$ ); pembuatan bokashi dan rumah pembibitan, serta pembuatan pupuk dan pestisida alami. Adanya penambahan pengetahuan, sikap dan ketrampilan terhadap upaya pemeliharaan lingkungan termasuk tanah dan air dengan memanfaatkan bahan local yang ada dibantu teknologi pertanian yang sesuai.

\section{UCAPAN TERIMA KASIH}

Kami mengucapkan terima kasih kepada Kemenristekdikti yang mendukung dana melalui DRPM 2018, mahasiswa Politani Kupang dan masyarakat Oelbiteno.

\section{DAFTAR PUSTAKA}

1) BPS Kabupaten Kupang, 2015. Indikator Ekonomi Kabupaten Kupang Tahun 2015. Website: https://kupangkab.bps.go.id/backend/pdf_publikasi/I ndikator-Ekonomi-Kabupaten-Kupang-Tahun2015.pdf. Diunduh pada 28 Februari 2017.

2) Jun, H., Xiang, He. 2011. Development of Circular Economy Is A Fundamental Way to Achieve Agriculture Sustainable Development in China. Energy Procedia 5: 1530-1534

3) Kirchherr, J., Reike, D., and Hekkert, M., 2017. Conceptualizing the circular economy: An analysis of 114 definitions. Resources, Conservation \& Recycling 127: 221-232.

4) Kuepper, G., 2001. Pursuing conservation tillage systems for organic crop production. ATTRA's Organic Matters. NCAT Agriculture specialist, June 2001.
5) Rupa, M., Klara, M., Kantur, D., Moata, M., 2017. Synchronization between Available Nitrogen and Maize (Zea Mays) Need: Study on Different Application Time and Type of Green Fertilizers. International Journal of Agriculture, Environment and Bioresearch Vol. 2, No. 05; 2017 ISSN: 24568643.

6) Moata, M.R.S., 2017. Evaluasi lahan dan Analysis Kesuburan Tanah di Dusun II, Desa Oelbiteno, Kecamatan Fatuleu Tengah, Kabupaten Kupang. Unpublished Laporan Penelitian. Prodi MPLK, Jurusan MLK Politani Kupang.

7) Moata, M.R.S., DeFrank, J., Deenik, J., Leary, J., 2009. Characterizing Heteropogoncontortus(piligrass) as living mulch for tropical vegetable crops. Thesis. Website:

8) https://www.ctahr.hawaii.edu/defrankJ/Text\%20reso urces/Living mulch 2009/M Moata thesis 1124 2009.pdf

9) Moata, M., et. al., 2018. Land optimalisation based on community farming system toward agroecotourism in Kupang regency, East Nusa Tenggara. Jurnal Dedikasi Masyarakat Umpar, Vol 1 No 2. ISSN 2598-7984, e-ISSN 25988018.

10) Natural Resource Conservation Service Soil, USDA. Calculated Coefficients of Linear Extensibility. Technical Resource. Di upload dari website:

11) https://www.nrcs.usda.gov/wps/portal/nrcs/main/soil s/survey/publication/diunduh pada 1 Maret 2017.

12) Padmini, O.S. 2011. Increasing Rice Production by Legumes Substituting On Crop Rotation and Organic Fertilizer To Develop Agrotourism. International Seminar on Agrotourism (ISAD). ISAD_23-07. Jogjakarta. http://eprints.upnyk.ac.id/13198/. Diunggah pada 28 Juli 2018.

13) Sainju, U., and Singh, B., 1997. Winter cover crops for sustainable agricultural systems: influence on soil properties, water quality, and crop yields. HortScience 32:21-28.

14) Schafer, W.M., and M.J. Singer. 1976. A new method of measuring shrink-swell potential using soil pastes. Soil Sci. Soc. Am. J. 40: 805-806.

15) Simon, J.J., L. Oosterhuis, and R.B. Reneau, Jr. 1987. Comparison of shrink-swell potential of seven ultisols and one alfisol using two different COLE techniques. Soil Sci. 143:50-55.

16) Yan, Z., Bi, J., and Moriuichi, Y., 2008. The Circular Economy: A new development strategy in China. Jurnal of Industrial Ecology. Doi: https://doi.org/10.1162/108819806775545321

17) Vaught, R., Brye, K.R., Miller, D. M., 2006. Relationships among Coefficient of Linear Extensibility and Clay Fractions in Expansive, Stoney Soils. Soil Sci. Soc. Am. J. 70:1983-1990 (2006). Soil Physics doi:10.2136/sssaj2006.0054. Madison-USA. 